\title{
Comparison of liver biopsy and transient elastography based on clinical relevance
}

\begin{abstract}
Ryota Masuzaki MD, Ryosuke Tateishi MD, Haruhiko Yoshida MD, Eriko Goto MD, Takahisa Sato MD, Takamasa Ohki MD, Tadashi Goto MD, Hideo Yoshida MD, Fumihiko Kanai MD, Yosuke Sugioka MT, Hitoshi Ikeda MD, Shuichiro Shiina MD, Takao Kawabe MD, Masao Omata MD
\end{abstract}

\begin{abstract}
R Masuzaki, R Tateishi, H Yoshida, et al. Comparison of liver biopsy and transient elastography based on clinical relevance. Can J Gastroenterol 2008;22(9):753-757.
\end{abstract}

BACKGROUND: Liver stiffness measurement (LSM) by transient elastography has recently been validated for the evaluation of liver fibrosis in chronic liver diseases. The present study focused on cases in which liver biopsy and LSM were discordant.

METHODS: Three hundred eighty-six patients with chronic hepatitis C who underwent a liver biopsy between December 2004 and April 2007 were studied. First, the optimal cut-off value of LSM was selected for the determination of cirrhosis based on the receiver operating characteristic curve. Then, the cases in which liver histology and evaluation by LSM were discordant were selected. Laboratory test results such as serum total bilirubin concentration, prothrombin activity, albumin concentration, platelet count and the aspartate aminotransferase to platelet ratio index, together with the presence of esophageal varices, were analyzed.

RESULTS: The optimal cut-off value was chosen to be $15.9 \mathrm{kPa}$ for cirrhosis (fibrosis stage $[\mathrm{F}]$ 4) determination to maximize the sum of sensitivity $(78.9 \%)$ and specificity $(81.0 \%)$. There were 78 discordant cases: 51 patients showed an LSM of $15.9 \mathrm{kPa}$ or higher and a fibrosis stage of F1 to F3 (high LSM group), and 27 patients had an LSM lower than $15.9 \mathrm{kPa}$ and a fibrosis stage of F4 (low LSM group). Esophageal varices were seen in 11 patients in the high LSM group $(\mathrm{n}=51)$ and in no patients in the low LSM group $(\mathrm{n}=27)(\mathrm{P}=0.0012)$. The aspartate aminotransferase to platelet ratio index was significantly higher in the high LSM group (1.49 versus 0.89, $\mathrm{P}=0.019$ ). Other parameters did not differ significantly. However, platelet count, prothrombin activity and albumin concentration tended to be lower in the high LSM group.

CONCLUSIONS: Patients with a high LSM need proper attention for cirrhosis, even if liver biopsy does not reveal cirrhosis.

Key Words: Hepatitis C; Liver biopsy; Liver fibrosis

The prognosis and clinical management of chronic liver diseases (CLDs) highly depend on the extent of liver fibrosis because life-threatening complications mainly occur in patients with cirrhosis $(1,2)$. This is particularly true of chronic hepatitis $\mathrm{C}$ virus (HCV) infection. Patients with cirrhosis are at high risk for hepatocellular carcinoma, liver failure and resulting death (3-8). This emphasizes the need for early identification of cirrhosis to screen for or prevent complications.
Une comparaison entre la biopsie hépatique et l'élastographie transitoire d'après la pertinence clinique

HISTORIQUE : La mesure de l'élasticité hépatique (MÉH) par élastographie transitoire a récemment été validée pour évaluer la fibrose hépatique en présence d'une maladie hépatique chronique. La présente étude portait sur les cas où les résultats de la biopsie hépatique et de la MÉH divergeaient.

MÉTHODOLOGIE : Les auteurs ont étudié 386 patients atteints d'hépatite $\mathrm{C}$ chronique ayant subi une biopsie hépatique entre décembre 2004 et avril 2007. D'abord, ils ont sélectionné la valeur seuil optimale de MÉH pour déterminer une cirrhose d'après la courbe de fonction d'efficacité du récepteur. Ensuite, ils ont retenu les cas à l'égard desquels l'histologie hépatique et l'évaluation par MÉH divergeaient. Ils ont analysé les résultats de tests de laboratoire comme la concentration bilirubinémique sérique totale, l'activité de la prothrombine, la concentration d'albumine, la numération plaquettaire et l'indice de ratio entre l'aspartate aminotransférase et les plaquettes, ainsi que la présence de varices œsophagiennes. RÉSULTATS : Les auteurs ont retenu la valeur seuil optimale de 15,9 kPa pour déterminer la cirrhose (stade de fibrose [F] 4) afin de maximiser la somme de sensibilité $(78,9 \%)$ et de spécificité $(81,0 \%)$. Ils ont repéré 78 cas divergents : 51 patients avaient une MÉH de 15,9 kPa ou plus et un stade de fibrose de F1 à F3 (groupe de MÉH élevé) et 27 patients, une MÉH inférieure à 15,9 kPa et un stade de fibrose de $\mathrm{F} 4$ (groupe de MÉH faible). Ils ont constaté des varices œesophagiennes chez 11 patients du groupe de MÉH élevé ( $\mathrm{n}=51)$ et chez aucun patient du groupe de MÉH faible $(n=27)(P=0,0012)$. L'indice de ratio entre l'aspartate aminotransférase et les plaquettes était considérablement plus élevé entre le groupe de MÉH élevé (1,49 par rapport à 0,89, $\mathrm{P}=0,019)$. Les autres paramètres ne différaient pas de manière significative. Cependant, la numération plaquettaire, l'activité de la prothrombine et la concentration d'albumine tendaient à être plus faibles dans le groupe de MÉH élevé.

CONCLUSIONS : Les patients dont la MÉH est élevée doivent subir une évaluation de cirrhose, même si la biopsie hépatique n'en révèle pas la présence.

Liver biopsy is currently considered to be the reference standard for the assessment of cirrhosis. However, it is an invasive procedure with rare, but severe, adverse events, including mortality (9). Its acceptance is limited, especially in asymptomatic patients. In addition, sampling error is common because only $1 / 50,000$ of the organ is analyzed, and a false negativity of up to $30 \%$ was reported when compared with surgically resected liver as a reference standard (10-12). Therefore, there

Department of Gastroenterology, University of Tokyo, Tokyo, Japan

Correspondence: Dr Haruhiko Yoshida, Department of Gastroenterology, University of Tokyo, 7-3-1 Hongo, Bunkyo-ku, Tokyo 113-8655,

Japan. Telephone 8-133-815-5411, fax 8-133-814-0021, e-mail yoshida-2im@h.u-tokyo.ac.jp

Received for publication February 6, 2008. Accepted May 30, 2008 
is a need to develop and validate noninvasive tests that can accurately reflect the full spectrum of hepatic fibrosis and cirrhosis, and their severity in liver diseases.

Both routine and specific biomarkers, together with combinations thereof, have been proposed as noninvasive indicators of the degree of liver fibrosis (13-16). However, these markers do not directly reflect the extent of fibrosis. Rather, they represent partial processes such as fibrogenesis and fibrolysis. Blood levels of some markers are affected by impaired metabolism in renal failure or cholestasis.

Transient elastography is a new, noninvasive and reproducible technique that measures tissue stiffness, which is mainly attributable to the extent of fibrosis. Liver stiffness measurement (LSM) by transient elastography has recently been validated for the evaluation of hepatic fibrosis in chronic liver diseases. However, various LSM cut-off values for cirrhosis have been reported to be between $12.5 \mathrm{kPa}$ and $17.6 \mathrm{kPa}(17-25)$, and no single cut-off value was accompanied by simultaneously high sensitivity and specificity. Ganne-Carrie et al (26) assessed 775 CLD patients of various etiologies and reported a sensitivity of $79 \%$ and a specificity of $95 \%$ using $14.6 \mathrm{kPa}$ as a cut-off value for fibrosis stage (F) 4 (cirrhosis). In assessing cirrhosis, discordant results were found between liver biopsy and LSM in 80 of 1007 patients (7.9\%). They re-analyzed the liver biopsy specimens and suggested that the main cause of the discordance was sampling variation of liver fibrosis assessed by liver biopsy.

Indeed, LSM is averaged over a volume that can be approximated by a cylinder $20 \mathrm{~mm}$ in height and $20 \mathrm{~mm}$ in diameter, which represents approximately $1 \%$ of the total liver volume and is 500-fold larger than the biopsy sample size. Therefore, LSM may be less likely to be affected by sampling error than liver biopsy and may be more relevant in the clinical assessment of CLD status. However, the discordance between liver biopsy and LSM has not been assessed in this respect.

In assessing the discordance between liver biopsy and LSM, it is difficult to choose an adequate reference standard. Because our primary aim was to compare liver biopsy with LSM in terms of clinical relevance, we compared the results of routine laboratory tests such as platelet count, albumin level and prothrombin activity, which are the earliest indicators of clinical cirrhosis (27-29). Our interest focused particularly on cases in which liver biopsy and LSM were discordant (ie, cases with a high LSM and noncirrhotic histology, and those with a low LSM and cirrhotic histology).

\section{PATIENTS AND METHODS}

\section{Patients}

Between December 2004 and April 2007, a total of 394 patients with chronic HCV underwent liver biopsy. Liver biopsies were indicated for the assessment of liver fibrosis before interferon therapy $(n=186)$, overall prognosis in patients suspected of having cirrhosis $(n=192)$ and liver function reservoir in patients with hepatocellular carcinoma before treatment $(n=16)$. LSM was performed within two weeks after liver biopsy. All patients were positive for serum HCV-RNA and showed at least transiently elevated serum alanine aminotransferase levels. Patients with ascites or hepatitis B virus coinfection were excluded from the current study. The study protocol conformed to the ethical guidelines of the 1975 Declaration of Helsinki and was approved by the University of Tokyo's (Tokyo, Japan) institutional review board (registration number 960). All patients fulfilling these criteria were enrolled after providing their written and informed consent. LSM by elastography was compared with the stage of liver fibrosis, laboratory test results and other patient characteristics.

\section{Methods}

LSM was performed using FibroScan (Echosens, France), a new medical device based on elastometry. The investigators previously underwent a training period in which each had performed at least 50 measurements. The procedure was totally noninvasive and was performed on the right lobe of the liver through the intercostal space. Only LSMs obtained in at least eight successful acquisitions with a success rate of at least $60 \%$ were considered reliable.

Liver biopsy was performed under ultrasonography by experienced hepatologists with a $16 \mathrm{G}$ Bard Monopty needle (Medicon Inc, Japan). The sample length was checked immediately after the procedure. When the sample length was less than $15 \mathrm{~mm}$, the biopsy was judged to be inappropriate and was repeated. Liver biopsy specimens were fixed in formalin and were paraffin-embedded. All biopsy specimens were analyzed by two experienced hepatopathologists blinded to the clinical data. Liver fibrosis was staged using a scale of 0 to 4 (F0, no fibrosis; F1, mild fibrosis; F2, moderate fibrosis; F3, severe fibrosis; F4, cirrhosis). The length and number of portal tracts (whether it contained five or more tracts) and the presence of fragmentation were checked based on the criteria by Regev et al (10).

Esophageal varices were evaluated by reviewing the reports of upper gastrointestinal endoscopies or multidetector computed tomography (CT) scans performed within three years before the LSM. CT scan findings of esophageal wall thickening, intraluminal protrusions or irregularities, or nodular enhancement within the esophageal wall were considered to be indicative of the presence of esophageal varices $(30,31)$.

In the analysis of discrepant cases, the optimal LSM cut-off value for the determination of cirrhosis was selected, as determined by liver biopsy histology, to maximize the sum of sensitivity and specificity based on the Youden index (32). Then, the cases in which there was a discordance between liver histology and evaluation by LSM were selected. There were two groups of discordant cases - those determined to be cirrhotic (F4) by LSM but noncirrhotic (F1 to F3) by histology, and those determined to be noncirrhotic by LSM but cirrhotic by histology. Laboratory test results of serum total bilirubin concentration, prothrombin activity, albumin concentration, platelet count and the aspartate aminotransferase to platelet ratio index (APRI) (14), together with the presence of esophageal varices, were compared between the two groups using unpaired Student's $t$ test for continuous variables and Fisher's exact probability test for categorical variables. All tests were two-sided, with a significance level of 5\%. Statistical analyses were performed with SPSS version 12 (SPSS Inc, USA).

\section{Patient characteristics}

\section{RESULTS}

A total of 394 patients underwent LSM within two weeks after liver biopsy. Eight patients were excluded because of unsuccessful measurements, which were mainly due to obesity (three patients had fewer than eight valid measurements and five had a success rate lower than 60\%). Thus, 386 patients were included in the current analysis. Their characteristics at the time of the LSM are summarized in 
TABLE 1

Baseline patient characteristics $(n=386)$

\begin{tabular}{|c|c|}
\hline Variable & Value \\
\hline Age, years, mean $\pm S D$ & $68.2 \pm 9.5$ \\
\hline Male sex, $\mathrm{n}(\%)$ & $227(58.8)$ \\
\hline Body mass index, $\mathrm{kg} / \mathrm{m}^{2}$, median (range) & $22.9(14.3-34.0)$ \\
\hline Alcohol consumption >80 g/day, n (\%) & $40(10.4)$ \\
\hline Aspartate aminotransferase, U/L, median (range) & $54(10-444)$ \\
\hline Alanine aminotransferase, U/L, median (range) & $47(6-506)$ \\
\hline Albumin, g/L, median (range) & $37(24-52)$ \\
\hline Total bilirubin, $\mu \mathrm{mol} / \mathrm{L}$, median (range) & $13.7(5.1-59.9)$ \\
\hline Platelet count, $\times 10^{9} / \mathrm{L}$, median (range) & $116(33-462)$ \\
\hline Prothrombin activity, \%, median (range) & $78.7(41.7-100.0)$ \\
\hline \multicolumn{2}{|l|}{ Liver biopsy finding, $\mathrm{n}(\%)$} \\
\hline Fibrosis stage $(F) 1$ & $29(7.5)$ \\
\hline $\mathrm{F} 2$ & $56(14.5)$ \\
\hline F3 & $82(21.2)$ \\
\hline $\mathrm{F} 4$ & $219(56.7)$ \\
\hline \multicolumn{2}{|l|}{ Qualities of biopsy specimen } \\
\hline Length, mm, median (range) & $16.2(15.2-17.3)$ \\
\hline$\geq 5$ portal tracts, $\mathrm{n}(\%)$ & $354(96.2)$ \\
\hline Not fragmented, n (\%) & $334(90.8)$ \\
\hline Liver stiffness, kPa, median (range) & $20.1(3.3-75)$ \\
\hline
\end{tabular}

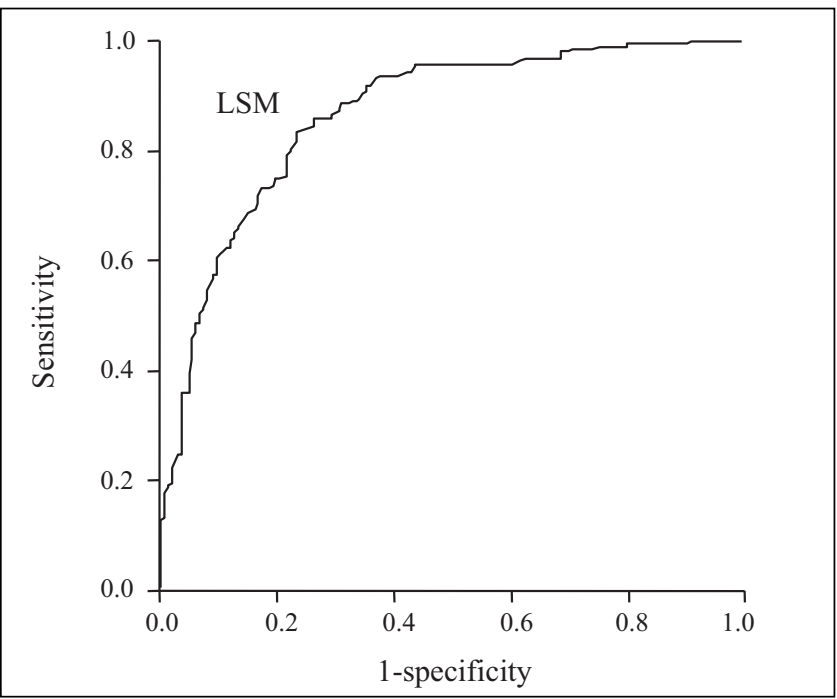

Figure 1) Receiver operating characteristic curve of liver stiffness measurement (LSM) accuracy for the diagnosis of cirrhosis in 386 patients. The area under the receiver operating characteristic curve of LSM was 0.87 (95\% CI 0.83 to 0.90)

Table 1. There were 277 men and 109 women, with a mean $( \pm$ SD) age of $68.2 \pm 9.5$ years. The frequency distribution of fibrosis stages on the precedent liver biopsy was F1 in 29 patients $(7.5 \%), \mathrm{F} 2$ in 56 patients $(14.5 \%), \mathrm{F} 3$ in 82 patients $(21.2 \%)$ and $\mathrm{F} 4$ in 219 patients $(56.7 \%)$. The median biopsy specimen length was $16.2 \mathrm{~mm}$.

Receiver operating curves

Figure 1 shows the diagnostic value (receiver operating characteristic curve) of LSM for the prediction of histologically diagnosed cirrhosis. The area under the receiver operating
TABLE 2

Cut-off value of liver stiffness measurement for cirrhosis

\begin{tabular}{lc}
\hline Variable & Cirrhosis \\
\hline Optimal cut-off, kPa* & 15.9 \\
Sensitivity, \% & 78.9 \\
Specificity, \% & 81.0 \\
Positive predictive value, \% & 87.2 \\
Negative predictive value, \% & 69.4 \\
Positive likelihood ratio & 4.15
\end{tabular}

*The optimal cut-off value was chosen to maximize the sum of sensitivity and specificity

TABLE 3

Differences in frequency distribution between the two discrepant groups

\begin{tabular}{lccc}
\hline Variable & $\begin{array}{c}\text { High LSM* } \\
(\mathbf{n = 5 1 )}\end{array}$ & $\begin{array}{c}\text { Low LSM } \\
(\mathbf{n = 2 7})\end{array}$ & $\mathbf{P}$ \\
\hline Esophageal varices, $\mathrm{n}(\%)$ & $11(21.6)$ & $0(0)$ & 0.0012 \\
Albumin, g/L & $37(24-45)$ & $39(28-45)$ & 0.269 \\
Prothrombin activity, \% & $79.2(60.7-100.0)$ & $82.9(63.0-97.1)$ & 0.754 \\
Total bilirubin, $\mu \mathrm{mol} / \mathrm{L}$ & $12.0(5.1-32.5)$ & $12.0(5.1-30.8)$ & 0.813 \\
APRI & $1.49(0.25-6.43)$ & $0.89(0.22-4.94)$ & 0.019 \\
Platelet count, $\times 10^{9} / \mathrm{L}$ & $112(39-269)$ & $123(46-255)$ & 0.062 \\
Qualities of biopsy specimen & & & 0.6246 \\
$\quad$ Length, mm & $16.2(15.2-16.8)$ & $16.4(15.3-17.2)$ & 0.606 \\
$\geq 5$ portal tracts, $\mathrm{n}(\%)$ & $49(96.1)$ & $25(92.6)$ & 0.606 \\
$\quad$ Not fragmented, $\mathrm{n}(\%)$ & $46(90.2)$ & $22(81.5)$ & 0.302 \\
\hline
\end{tabular}

Data are expressed as median (range), unless otherwise specified. *Liver stiffness measurement (LSM) of $15.9 \mathrm{kPa}$ or higher and fibrosis stage ( $F$ ) 1 to F3; ${ }^{+}$LSM lower than $15.9 \mathrm{kPa}$ and F4. APRI Aspartate aminotransferase to platelet ratio index

characteristic (AUROC) curve is the most commonly used method of summarizing overall accuracy; an area of 1 represents a perfect test and an area of 0.5 or lower represents a noninformative test. The AUROC curve of LSM was 0.87 (95\% CI 0.83 to 0.90$)$. The optimal cut-off value was chosen to be $15.9 \mathrm{kPa}$ for F4 determination to maximize the sum of sensitivity $(78.9 \%)$ and specificity $(81.0 \%$ ) (Table 2 ).

Discordance analysis

Using the LSM cut-off value of $15.9 \mathrm{kPa}$, there were 78 cases of discordance between LSM and stage of fibrosis: 51 patients showed an LSM of $15.9 \mathrm{kPa}$ or higher and a fibrosis stage of F1 to F3 (high LSM group), and 27 patients had an LSM lower than $15.9 \mathrm{kPa}$ and a fibrosis stage of F4 (low LSM group). Among the patients in the high LSM group, the distribution of histological fibrosis stage was F2 in 10 patients and F3 in 41 patients. Clinical factors were compared between the two groups (Table 3). Esophageal varices were seen in 11 of 51 patients in the high LSM group and in none of the 27 patients in the low LSM group $(\mathrm{P}=0.0012)$. Fibrosis stages seen in these patients were F2 in two patients and F3 in nine. The APRI was significantly higher in the high LSM group $(\mathrm{P}=0.019)$, indicating higher aspartate aminotransferase levels or lower platelet count. Although other parameters did not differ significantly between the two groups, platelet count, prothrombin activity and albumin concentration tended to be lower in the high LSM group. 
TABLE 4

Cut-off values of liver stiffness measurement for cirrhosis

\begin{tabular}{lccc}
\hline Reference & $\begin{array}{c}\text { Cut-off value for } \\
\text { cirrhosis, kPa }\end{array}$ & Sensitivity, \% & Specificity, \% \\
\hline Castera et al (18) & 12.5 & 87 & 91 \\
Ziol et al (25) & 14.6 & 86 & 96 \\
Foucher et al (20) & 17.6 & 77 & 97 \\
Ganne-Carrie et al (26) & & & \\
Cohort 1 & 17.1 & 76 & 95 \\
Cohort 2 & 14.6 & 79 & 95 \\
\hline
\end{tabular}

\section{DISCUSSION}

In the present study, we prospectively assessed transient elastography and showed that the AUROC for the prediction of F4 was as large as 0.89 . The optimal cut-off value for F4 was found to be $15.9 \mathrm{kPa}$, with a sensitivity of $78.9 \%$ and a specificity of $81.0 \%$. These figures indicate that LSM is a reliable diagnostic test for cirrhosis, as previously demonstrated (Table 4). However, the question remains as to whether the discordance between liver biopsy and LSM represents a random error or a systematic bias (ie, whether there is a tendency to over- or underestimate liver fibrosis in either procedure).

Liver biopsy has been used as the gold standard for the evaluation of other tests for liver fibrosis. However, the reliability of liver biopsy has been questioned. Using the METAVIR scoring system, Bedossa et al (33) showed that only $65 \%$ of samples from a $15 \mathrm{~mm}$-long needle liver biopsy (which is the currently recommended length) were correctly classified in terms of fibrosis stage compared with the surgical sample. The concordance rate increased to $75 \%$ using $25 \mathrm{~mm}$-long specimens. Therefore, the discordance found in the present study was likely caused by random sampling errors due to the small specimen size and the heterogeneity of fibrosis in the liver. However, this leads to a biased error in favour of overall overestimation when applied to the uppermost category (F4), and the proportion of overestimation depends on the size of random errors. Similarly, a portion of F4 cases are underestimated and misdiagnosed as F3. However, this is counterbalanced by an overestimation of F2 into F3; the overall effects on intermediate categories such as F3 are less biased.

When two tests differ in their diagnosis of cirrhosis, the test with the smaller number of sampling errors is less likely to overestimate the stage of fibrosis and more likely to be accurate (34). Assuming that sampling errors in liver biopsy and those in LSM are mutually independent, and that LSM is associated with fewer sampling errors, fewer noncirrhotic patients are falsely diagnosed to be cirrhotic by LSM than by liver biopsy. This becomes especially important, clinically, when the results of the two assessments differ. In the current analysis, esophageal varices, which are an important stigma of cirrhosis, were found in 11 of 51 patients $(21.6 \%)$ in the high LSM group but in none of the 27 patients in the low LSM group. Esophageal varices not only cause death in cirrhotic patients directly by rupture but are also reported to indicate a risk of transition from the compensated to the decompensated stages of cirrhosis (35). Consequently, screening for esophageal varices is strongly recommended for patients with a high LSM, regardless of liver biopsy results.

APRI is reported to be an accurate predictor of cirrhosis, showing an AUROC curve of 0.89 in the training set and 0.88 in the validation set (14). In the present study, the APRI was significantly higher in the high LSM group than in the low LSM group, supporting the hypothesis that LSM is more accurate than liver biopsy histology. Serum albumin concentration was lower and bilirubin concentration was higher in the high LSM group than in the low LSM group, although the difference was not significant. These indexes are associated with the prognosis of cirrhotic patients and are built into the ChildPugh classification (36). It is possible that LSM is also a good predictor of prognosis in CLD patients. Poynard et al (37) assessed the discordant results between biochemical markers and biopsy in patients with chronic HCV. Their results suggested that 97 of $154(62.9 \%)$ discordant cases were due to biopsy failure. Our results also suggested that approximately two-thirds of discordant cases were due to liver biopsy failure rather than LSM failure.

\section{Limitations}

The present study has some limitations. First, a large proportion of patients had cirrhosis or precirrhosis. Most underwent liver biopsy for the evaluation of suspected cirrhosis or in preparation for interferon therapy, which required ruling out a diagnosis of cirrhosis. Second, we adopted the cut-off value of $15.9 \mathrm{kPa}$ to maximize the sum of sensitivity and specificity in the current study population. This does not mean that this value is universally optimal. Finally, although the diagnosis of varices using a CT scan is fairly specific, it is not sensitive, which may have led to an underestimation of varices or portal hypertension.

Due to the lack of an appropriate gold standard for assessing the degree of liver fibrosis, the cross-sectional comparison between liver biopsy and LSM that was attempted in the current study has its limitations. Nevertheless, the results of the present study have suggested that LSM is less likely to underestimate cirrhosis than liver biopsy. Patients with a high LSM require proper attention, even if liver biopsy assessment determines no cirrhosis. After all, the primary purpose of assessing fibrosis in CLD patients is to predict decompensation, carcinogenesis and overall survival. The clinical relevance of LSM in this respect is to be confirmed in future prospective studies. If LSM is confirmed as an effective predictor of cirrhosis, liver biopsy may be reserved for the assessment of etiology or the grading of necroinflammatory activity.

\section{CONCLUSION}

Patients with a high LSM need proper attention for cirrhosis, even if liver biopsy does not reveal cirrhosis.

\section{REFERENCES}

1. Poynard T, Bedossa P, Opolon P. Natural history of liver fibrosis progression in patients with chronic hepatitis C. The OBSVIRC, METAVIR, CLINIVIR, and DOSVIRC groups. Lancet 1997;349:825-32.

2. Tsukuma H, Hiyama T, Tanaka S, et al. Risk factors for hepatocellular carcinoma among patients with chronic liver disease. N Engl J Med 1993;328:1797-801.

3. Fattovich G, Giustina G, Degos F, et al. Morbidity and mortality in compensated cirrhosis type C: A retrospective follow-up study of 384 patients. Gastroenterology 1997;112:463-72.

4. Yoshida H, Shiratori Y, Moriyama M, et al. Interferon therapy reduces the risk for hepatocellular carcinoma: National surveillance program of cirrhotic and noncirrhotic patients with chronic hepatitis C in Japan. IHIT Study Group. Inhibition of Hepatocarcinogenesis by Interferon Therapy. Ann Intern Med 1999;131:174-81. 
5. Benvegnu L, Gios M, Boccato S, Alberti A. Natural history of compensated viral cirrhosis: A prospective study on the incidence and hierarchy of major complications. Gut 2004;53:744-9.

6. Degos F, Christidis C, Ganne-Carrie N, et al. Hepatitis C virus related cirrhosis: Time to occurrence of hepatocellular carcinoma and death. Gut 2000;47:131-6.

7. Hu KQ, Tong MJ. The long-term outcomes of patients with compensated hepatitis $\mathrm{C}$ virus-related cirrhosis and history of parenteral exposure in the United States. Hepatology 1999;29:1311-6.

8. Omata M, Yoshida H, Shiratori Y. Prevention of hepatocellular carcinoma and its recurrence in chronic hepatitis $\mathrm{C}$ patients by interferon therapy. Clin Gastroenterol Hepatol 2005;3(Suppl 2):S141-3.

9. Dienstag JL. The role of liver biopsy in chronic hepatitis C. Hepatology 2002;36(Suppl 1):S152-60.

10. Regev A, Berho M, Jeffers LJ, et al. Sampling error and intraobserver variation in liver biopsy in patients with chronic HCV infection. Am J Gastroenterol 2002;97:2614-8.

11. Intraobserver and interobserver variations in liver biopsy interpretation in patients with chronic hepatitis C. The French METAVIR Cooperative Study Group. Hepatology 1994;20:15-20.

12. Maharaj B, Maharaj RJ, Leary WP, et al. Sampling variability and its influence on the diagnostic yield of percutaneous needle biopsy of the liver. Lancet 1986;1:523-5.

13. Le Calvez S, Thabut D, Messous D, et al. The predictive value of Fibrotest vs. APRI for the diagnosis of fibrosis in chronic hepatitis C. Hepatology 2004;39:862-3.

14. Wai CT, Greenson JK, Fontana RJ, et al. A simple noninvasive index can predict both significant fibrosis and cirrhosis in patients with chronic hepatitis C. Hepatology 2003;38:518-26.

15. Qiu Y, Hoshida Y, Kato N, et al. A simple combination of serum type IV collagen and prothrombin time to diagnose cirrhosis in patients with chronic active hepatitis C. Hepatol Res 2004;30:214-20.

16. Fontana RJ, Lok AS. Noninvasive monitoring of patients with chronic hepatitis C. Hepatology 2002;36(Suppl 1):S57-64.

17. Castera L, Foucher J, Bertet J, Couzigou P, de Ledinghen V. FibroScan and FibroTest to assess liver fibrosis in HCV with normal aminotransferases. Hepatology 2006;43:373-4.

18. Castera L, Vergniol J, Foucher J, et al. Prospective comparison of transient elastography, Fibrotest, APRI, and liver biopsy for the assessment of fibrosis in chronic hepatitis C. Gastroenterology 2005; $128: 343-50$

19. de Ledinghen V, Douvin C, Kettaneh A, et al. Diagnosis of hepatic fibrosis and cirrhosis by transient elastography in HIV/hepatitis C virus-coinfected patients. J Acquir Immune Defic Syndr 2006;41:175-9.

20. Foucher J, Chanteloup E, Vergniol J, et al. Diagnosis of cirrhosis by transient elastography (FibroScan): A prospective study. Gut 2006;55:403-8.
21. Kazemi F, Kettaneh A, N'kontchou G, et al. Liver stiffness measurement selects patients with cirrhosis at risk of bearing large oesophageal varices. J Hepatol 2006;45:230-5.

22. Sandrin L, Fourquet B, Hasquenoph JM, et al. Transient elastography: A new noninvasive method for assessment of hepatic fibrosis. Ultrasound Med Biol 2003;29:1705-13.

23. Fraquelli M, Rigamonti C, Casazza G, et al. Reproducibility of transient elastography in the evaluation of liver fibrosis in patients with chronic liver disease. Gut 2007;56:968-73.

24. Nahon P, Thabut G, Ziol M, et al. Liver stiffness measurement versus clinicians' prediction or both for the assessment of liver fibrosis in patients with chronic hepatitis C. Am J Gastroenterol 2006;101:2744-51.

25. Ziol M, Handra-Luca A, Kettaneh A, et al. Noninvasive assessment of liver fibrosis by measurement of stiffness in patients with chronic hepatitis C. Hepatology 2005;41:48-54.

26. Ganne-Carrie N, Ziol M, de Ledinghen V, et al. Accuracy of liver stiffness measurement for the diagnosis of cirrhosis in patients with chronic liver diseases. Hepatology 2006;44:1511-7.

27. Matsumura H, Moriyama M, Goto I, Tanaka N, Okubo H, Arakawa Y. Natural course of progression of liver fibrosis in Japanese patients with chronic liver disease type $\mathrm{C}$ - a study of 527 patients at one establishment. J Viral Hepat 2000;7:268-75.

28. Oberti F, Valsesia E, Pilette C, et al. Noninvasive diagnosis of hepatic fibrosis or cirrhosis. Gastroenterology 1997;113:1609-16.

29. Lok AS, Ghany MG, Goodman ZD, et al. Predicting cirrhosis in patients with hepatitis $\mathrm{C}$ based on standard laboratory tests: Results of the HALT-C cohort. Hepatology 2005;42:282-92.

30. Balthazar EJ, Naidich DP, Megibow AJ, Lefleur RS. CT evaluation of esophageal varices. AJR Am J Roentgenol 1987;148:131-5.

31. Kim YJ, Raman SS, Yu NC, To'o KJ, Jutabha R, Lu DS. Esophageal varices in cirrhotic patients: Evaluation with liver CT. AJR Am J Roentgenol 2007;188:139-44

32. Youden WJ. Index for rating diagnostic tests. Cancer 1950;3:32-5.

33. Bedossa P, Dargere D, Paradis V. Sampling variability of liver fibrosis in chronic hepatitis C. Hepatology 2003;38:1449-57.

34. Ratziu V, Charlotte F, Heurtier A, et al; LIDO Study Group. Sampling variability of liver biopsy in nonalcoholic fatty liver disease. Gastroenterology 2005;128:1898-906.

35. D'Amico G, Morabito A, Pagliaro L, Marubini E. Survival and prognostic indicators in compensated and decompensated cirrhosis. Dig Dis Sci 1986;31:468-75.

36. Lawson A, Hagan S, Rye K, et al; Trent HCV Study Group. The natural history of hepatitis $\mathrm{C}$ with severe hepatic fibrosis. J Hepatol 2007;47:37-45.

37. Poynard T, Munteanu M, Imbert-Bismut F, et al. Prospective analysis of discordant results between biochemical markers and biopsy in patients with chronic hepatitis C. Clin Chem 2004;50:1344-55. 


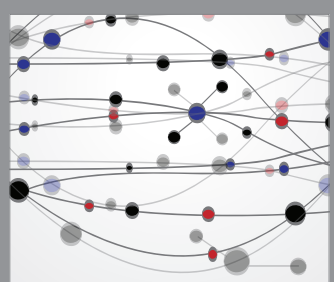

The Scientific World Journal
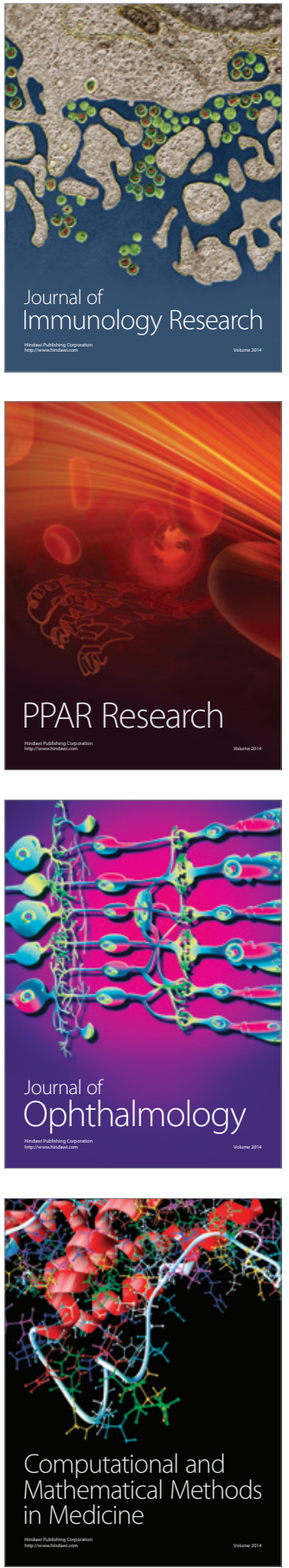

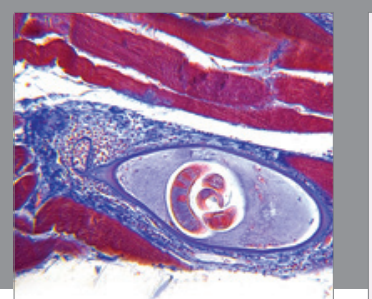

Gastroenterology Research and Practice

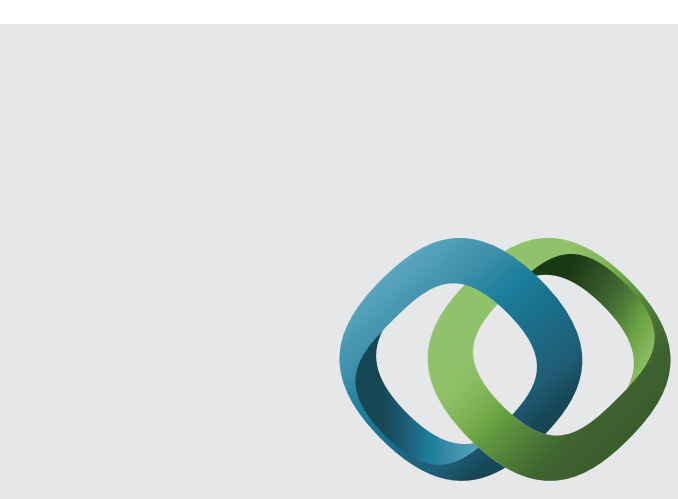

\section{Hindawi}

Submit your manuscripts at

http://www.hindawi.com
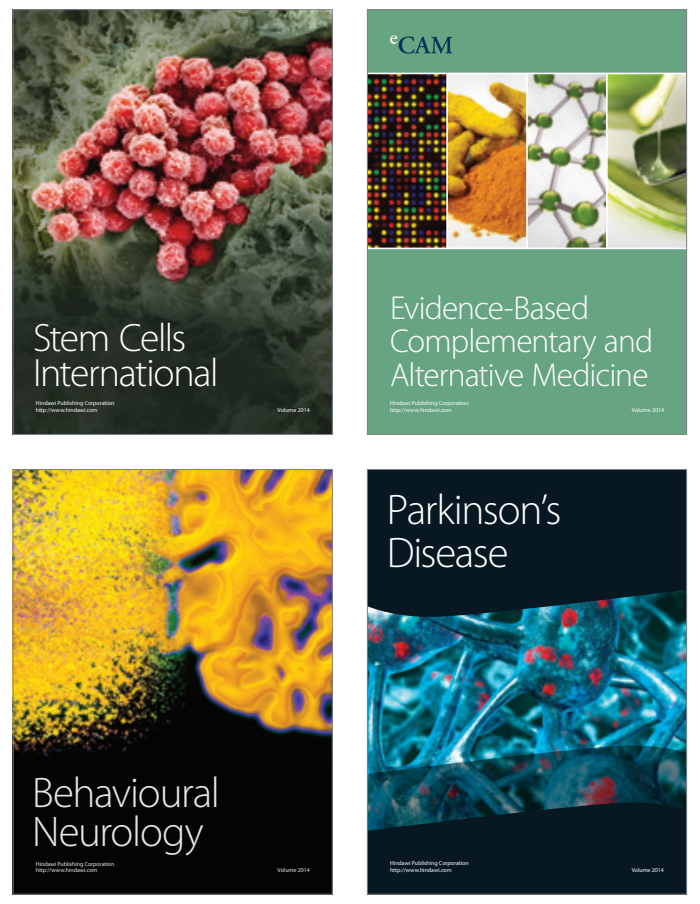
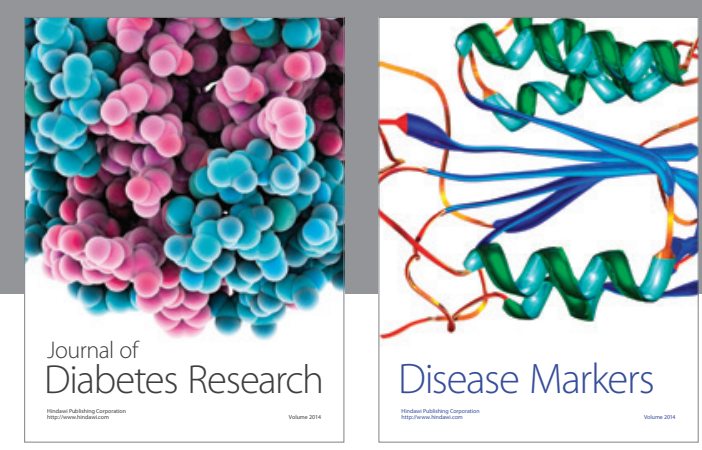

Disease Markers
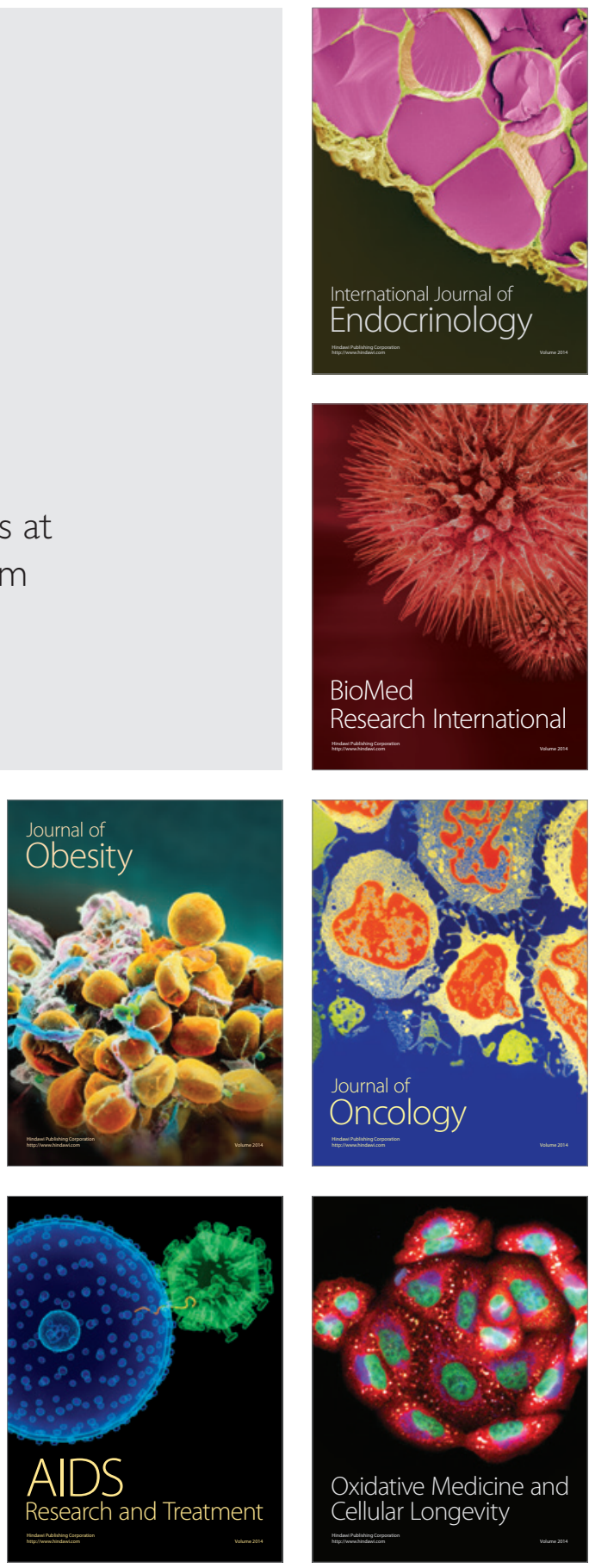